\title{
Do Face Masks Increase the Rate of Staphylococcus Aureus Infection as Secondary Infection during Covid-19?
}

Mahdi Bozorgnia ${ }^{1 *}$, Alireza Bozorgnia ${ }^{2}$ and Shahriar Gharibzadeh ${ }^{3}$

${ }^{1}$ Faculty of Pharmacy, Comenius University in Bratislava, Bratislava, Slovakia.

${ }^{2}$ Faculty of Microbiology, Islamic Azad University, Iran.

${ }^{3}$ Associate Professor, Cognitive Rehabilitation Clinic, Shahid Behesthi University, Tehran, Iran.

*Corresponding author: Mahdi Bozorgnia, Faculty of Pharmacy, Comenius University in Bratislava, Bratislava, Slovakia.

Received date: June 2, 2021; Accepted date: June 7, 2021; Published date: June 11, 2021

Citation: Mahdi Bozorgnia, Alireza Bozorgnia and Shahriar Gharibzadeh (2021). Do Face Masks Increase the Rate of Staphylococcus Aureus Infection as Secondary Infection during Covid-19? J Clinical Research and Reports, 8(2); DOI:10.31579/2690-1919/177

Copyright: (c) 2021 Mahdi Bozorgnia. This is an open access article distributed under the Creative Commons Attribution License, which permits unrestricted use, distribution, and reproduction in any medium, provided the original work is properly cited.

\begin{abstract}
Nowadays due to the coronavirus disease 2019 (COVID-19) and to save our lives, we have to use masks in a wider range. Since masks are now considered a protective device to prevent some bacterial or viral diseases, especially COVID-19, and the advice is that we should use them to save our lives and the lives of others. It is true that masks have many benefits, but maybe they are also harmful. It seems that is possible in long- term masking, itself cause side effects or even other diseases. Therefore, since masks are now more widely used, its advantages and even disadvantages are important to us. We think, maybe there are harms that may cause other bacterial diseases as secondary bacterial infection that may be confused with COVID-19 because they may have similar symptoms or may increase the severity of it. In this article, we review Staphylococcus Aureus that may be exacerbate or cause infectious diseases and increase the risk of infection. We may be able to prevent them with some recommendations.

Keywords: staphylococcus aureus; face mask; Covid-19; infectious diseases; SARS; MERS; ARDS; WHO; FFR, symptoms; pneumonia
\end{abstract}

\section{Introduction}

\section{Coronavirus and secondary bacterial infections}

In December 2019, a group of acute respiratory disease, nowadays known as novel coronavirus-infected pneumonia (NCIP), occurred in Wuhan, China [1]. The disease has quickly spread from Wuhan to different regions and got pandemic.

Three bronchoalveolar-lavage samples were collected from Wuhan Jinyintan Hospital on 30 December 2019. The novel coronavirus was identified when, Genome sequences were checked and have $86.9 \%$ nucleotide sequence of bat SARS-like CoV that also shows the typical betacoronavirus organization and was confirmed as the cause of the NCIP [2].

Analysis had shown that 2019-nCoV is a distinct from betacoronaviruses associated with human severe acute respiratory syndrome (SARS) and Middle East respiratory syndrome (MERS). The 2019-nCoV is very similar to bat coronaviruses, and it has been presumed that bats are the primary source [2]. While the origin of the 2019-nCoV is still unknown, recent evidence proposes spread to humans happened via transmission from wild animals illegally sold in the Huanan Seafood Wholesale Market. Case reports proofed human-to-human transmission of NCIP [3].

First clinical symptoms included decreased leukocyte counts, dyspnea, fatigue, fever, myalgia, nonproductive cough, normal and pneumonia. Organ dysfunction i.e., acute cardiac injury, and acute kidney injury, acute respiratory distress syndrome [ARDS], shock and death can happen in severe cases [4]. In addition, the difference in clinical characteristics between severe and non-severe cases has not been reported yet.

Globally, as of 4 June 2021 approximately 171,782,908 confirmed cases of coronavirus disease 2019 (COVID-19) caused by the 2019 novel coronavirus (SARS-CoV-2) including an estimated 3,698,621 deaths have been reported to world Health Organization (WHO).

The focus is needed on prevention and treatment of this viral infection.

Since coronavirus disease 2019 (COVID-19), using of face masks has become ubiquitous [5]. Using face masks by healthy population in the community to minimize risk of spread of respiratory viruses stays disputable. The effect of community-wide mask usage in order to control COVID-19 has been evaluated. Community-wide mask wearing may contribute to the control of COVID-19 by minimizing the amount of emission of infected saliva and respiratory droplets from persons with subclinical or COVID-19 [6].

Using masks is part of a comprehensive package of the prevention and control measures that can limit the spread of COVID-19. Masks can be used either for protection of healthy persons, worn to protect oneself when in contact with an infected individual or for source control, worn by an infected individual to prevent onward transmission [7]. Face mask is critical for protecting health care workers in hospitals and clinics and reduces the spread of the COVID-19. 
Pulmonary diseases of viral origin are often followed by the manifestation of secondary infections, may leading to more clinical complications and negative disease results [8]. Then, investigation of secondary infections is important. Data was provided for COVID-19 patients, a mortality rate is higher due to secondary bacterial infections [9]. Quinolones, cephalosporins and macrolides are commonly prescribed, but also the glycopeptide vancomycin [10]. Several bacterial pathogens appear to be common causes of secondary infections, including antibiotic-resistant strains of Staphylococcus aureus and Klebsiella pneumoniae [8].

\section{Staphylococcus aureus}

Staphylococcus aureus is an aerobic that can also, can live in anaerobic conditions and is Gram-positive coccus. S. aureus is found in the environment, also in normal human flora, located on the skin and mucous membranes (most often the nasal area) of most healthy individuals. S. aureus does not normally cause infection on healthy skin; however, if it enters the bloodstream or internal tissues, these bacteria may cause a variety of serious infections [11]. One of major risk factors for Staphylococcus aureus infection is nasal carriage around $25 \%$ of adults carry this bacterium [12]. The percentages are higher for people who are patients in a hospital or who work there. Staphylococcus aureus is a leading cause of life-threatening infections [13]. Paradoxically, it also asymptomatically colonizes approximately $20 \%-30 \%$ of healthy adults. Nasal carriage of $S$. aureus has been shown to be a major risk factor for ensuing $S$. aureus infection [14].

Local skin humidity and temperature are highly conducive to the growth of $S$. aureus [15]. Increases in humidity as well as temperature have been both associated with significantly higher culturable bacteria in indoor air [16].

Different individual factors, including loss of the normal skin barrier, existence of some illnesses such as acquired immunodeficiency syndrome, defects in neutrophils function and diabetes put at risk of infection $[17,18]$. The primary way of transmission of $S$. aureus is by direct contact, commonly skin-to-skin contact with infected persons or those how have it, also by contacting with contaminated surfaces and stuffs could play a role. Antibiotic-resistant strains of S. aureus leads to infection that have become global epidemic. Staphylococcal disease, especially that caused by methicillin resistant $S$. aureus strains (MRSA), is increasing. S. aureus is a remarkable compatible pathogen with a proofed ability to provide and develop resistance. Of particular concern is beta-lactam antibiotics diminishing impacts. Resistance is often seen as consequence of gene transmission that is prevalent in hospitals and healthcare institutions. Although the discovery and development of new antimicrobials is essential, the problem of drug resistance seems unlikely to be solved for a long time [19]. To prevent the emergence of the postantibiotic era, new technologies are needed that lead to faster and faster diagnosis, better understanding of the pathogenicity of S. aureus and nonantimicrobial approaches to prevention and treatment of infection [20].

As we mentioned earlier one the most common bacterial infections in humans, is S. aureus which may cause human infections including: bacteremia, infective endocarditis, skin and soft tissue infections e.g., impetigo, folliculitis, furuncles, carbuncles, cellulitis, scalded skin syndrome, and others, osteomyelitis, septic arthritis, prosthetic device infections, pulmonary infections e.g., pneumonia and empyema, gastroenteritis, meningitis, toxic shock syndrome, and urinary tract infections [11].

\section{Is it a problem as a secondary infection in covid-19 patients?}

In COVID-19 patients, Staphylococcus aureus is one of the common bacteria isolated during secondary infections [21]. During active viral infections, the course of the infection, proximity of infection and virulence factors vary between bacterial strains, resulting in different outcomes.

Effective treatment of viral and secondary bacterial infection(s) is a vital importance. Deployed antiviral therapies do not initially treat secondary bacterial infections [22].

The preferred treatment for bacterial infections is normally broadspectrum antibiotics, but this can lead to adversely affect the natural microflora of the host [23]. To reduce severe disease progression or fatal outcomes, alternative methods are needed to alleviate the effects of secondary bacterial infections and eliminate bacterial pathogens while maintaining host immunity.

\section{Face mask}

Masks have been used more than 100 years to minimize some bacterial or viral infections [24,25]. Also, it has been showed that dual respiratory virus or bacterial-viral infections can be reduced by the use of N95 respirators [26]. In addition, masks can consider respiratory protection devices. Because they filter out fine airborne particles from reaching the respiratory system and prevent interpersonal infection, the protective effect of face mask is important [27].

After exposure to masks for hours, hot and humid environment in the facial region that covered by masks, makes discomfort such as change in physiological function of nasal cavity and hyperthermia [28]. The high temperature also, high moisture content of the exhaled breath can make moisture to condense in filtering face piece respirators (FFR) due to difference of temperature between ambient air and that in the FFR dead space. The amount of moisture retained within FFR is impacted by the breathing volume, ambient temperature and humidity. It is possible that more water retention and added impact on breathing resistances could occur with use over an 8-h period. The amount of water vapor present in saturated air depends on the air temperature [29]. Some data suggest that exhaled breath temperatures may be $1-2^{\circ} \mathrm{C}$ higher in healthy adults. Each $1{ }^{\circ} \mathrm{C}$ rise in temperature increases water vapor pressure $6-7.5 \%$ so that the absolute increase in expelled moisture (and resultant retained moisture in the FFR) at the higher temperature would be increased proportionally [30]. One study indicated that fitting a surgical mask or respirator during $1 \mathrm{~h}$ of continuous wearing led to an increase in facial skin temperature under the face mask, while removing the face mask tended to rapidly decrease it after $1 \mathrm{~min}$, returning to the baseline after $5 \mathrm{~min}$ [31]. Wearing a face mask may increase the oral temperature in healthy persons [32]. A high increase of humidity and temperature at the end of inspiration was found in the prior nasal part [33].

Wearing masks for a long time causes a lot of physiological and psychological loads and can reduce work efficiency. The activity cannot be performed as much or as efficiently while wearing the mask as when the masks are not worn. In addition, when you can continue an activity, it decreases when using the mask. Prolonged use of N95 and surgical masks can cause physical side effects such as acne, difficulty breathing, headaches, impaired cognition, rashes, and skin breakdown. It also interferes with vision, communication, and thermal balance [34].

Also pain behind the ear and on nose which are possibly due to the tightfitting masks. Some people experience shortness of breath or trouble breathing on exertion when using mask, possibly due to the tight mask that causes hypercapnic hypoxic atmosphere and leads to number of physiological changes, including cardio-respiratory stress and metabolic changes. Other symptoms such as dry mouth, halitosis, and sore throat are most likely due to insufficient water intake during long-term usage of facemask [35]. Also, small proportion of people have been observed with symptoms of odor change, sense of nasal stuffiness, nasal obstruction, cracking sensation, nasal scab [35]. 


\section{Recommendation}

Survey respondents have recommended to prevent headaches and impaired cognition, it is recommended to take short and continuous breaks, neck massage, increased hydration, alternate surgical masks and N95 masks (if possible) because Continuous use of N95s resulted in significantly lower rates of bacterial colonization [36] and have more protective advantages [37], wearing an N95 mask with a filter for better ventilation, and wearing a mask that fits person's face.

To prevent skin breakdown, it is recommended to use an ear protection, so that earplugs are placed on those protective items instead of behind the ears. Also recommended to use a clean and fresh mask for each shift to remove broken skin. As a precaution such as using moisturizers, emollients, and barrier creams to prevent skin damage. It should be noted that dressings, moisturizers, and lotions do not interact with mask seal, thus causing decreased protection against COVID-19 particles. At the end, to prevent acne, avoiding facial makeup, moisturizing skin, and using facial cleanser wipes to cleanse the skin and Wash your face in the morning and at the end of the day with a gentle, fragrance and nonmedicated cleanser [38]. Also recommended to improved mask design with a focus on safety, comfort, and tolerability [34].

We suggest everyone that uses face mask for long period of time, should remove it periodically for regulating temperature and humidity and preventing S. aureus infection. And at the end our other suggestion is to design safe and comfortable mask without side effects that can cause other infections or design mask with special substances like dehumidifiers or cooling the air that is inside of mask.

\section{Conclusion}

We have to use mask because it has lots of benefits more than harms. The use of face mask may play a major role in causing significant discomfort to most of persons during long-term use, which can limit the effective use of face mask and reduce protection. On the other hand, face masks are essential to protect us from COVID-19 and some certain strategies can be followed to reduce risks of using mask. Based on abovementioned points, we think that using face masks may increase the rate of S. aureus infection. As one of the symptoms of S. aureus is pneumonia, could be considered as corona not $\mathrm{S}$. aureus that has to be checked.

\section{References:}

1. Hui, D. S., Azhar, E. I., Madani, T. A., Ntoumi, F., Kock, R., Dar, O. \& Zumla, A. (2020). The continuing 2019-nCoV epidemic threat of novel coronaviruses to global health-The latest 2019 novel coronavirus outbreak in Wuhan, China. International Journal of Infectious Diseases, 91, 264266.

2. Zhu, N., Zhang, D., Wang, W., Li, X., Yang, B., Song, J. \& Niu, P. (2020). A novel coronavirus from patients with pneumonia in China, 2019. New England Journal of Medicine.

3. Wang, D., Hu, B., Hu, C., Zhu, F., Liu, X., Zhang, J. \& Zhao, Y. (2020). Clinical characteristics of 138 hospitalized patients with 2019 novel coronavirus-infected pneumonia in Wuhan, China. Jama, 323(11), 1061-1069.

4. Yang, X., Yu, Y., Xu, J., Shu, H., Liu, H., Wu, Y. \& Wang, Y. (2020). Clinical course and outcomes of critically ill patients with SARS-CoV-2 pneumonia in Wuhan, China: a singlecentered, retrospective, observational study. The Lancet Respiratory Medicine.

5. Feng, S., Shen, C., Xia, N., Song, W., Fan, M., \& Cowling, B. J. (2020). Rational use of face masks in the COVID-19 pandemic. The Lancet Respiratory Medicine, 8(5), 434-436.

6. Cheng, V. C., Wong, S. C., Chuang, V. W., So, S. Y., Chen, J. H., Sridhar, S. \& Yuen, K. Y. (2020). The role of community- wide wearing of face mask for control of coronavirus disease 2019 (COVID-19) epidemic due to SARS-CoV-2. Journal of Infection.

7. World Health Organization. (2020). Advice on the use of masks in the context of COVID-19: interim guidance, 5 June 2020 (No. WHO/2019-nCov/IPC_ Masks/2020.4). World Health Organization.

8. Manohar, P., Loh, B., Nachimuthu, R., Hua, X., Welburn, S. C., \& Leptihn, S. (2020). Secondary bacterial infections in patients with viral pneumonia. Frontiers in medicine, 7, 420.

9. Azhar, E. I., Hui, D. S., Memish, Z. A., Drosten, C., \& Zumla, A. (2019). The Middle East Respiratory Syndrome (MERS). Infectious Disease Clinics, 33(4), 891-905.

10. Arabi, Y. M., Arifi, A. A., Balkhy, H. H., Najm, H., Aldawood, A. S., Ghabashi, A. \& Al Raiy, B. (2014). Clinical course and outcomes of critically ill patients with Middle East respiratory syndrome coronavirus infection. Annals of internal medicine, 160(6), 389-397.

11. Taylor, T. A., \& Unakal, C. G. (2017). Staphylococcus aureus.

12. Kuehnert, M. J., Kruszon-Moran, D., Hill, H. A., McQuillan, G., McAllister, S. K., Fosheim, G., \& Tenover, F. C. (2006). Prevalence of Staphylococcus aureus nasal colonization in the United States, 2001-2002. Journal of Infectious Diseases, 193(2), 172-179.

13. Lin, D., Ou, Q., Lin, J., Peng, Y., \& Yao, Z. (2017). A metaanalysis of the rates of Staphylococcus aureus and methicillinresistant $S$ aureus contamination on the surfaces of environmental objects that health care workers frequently touch. American journal of infection control, 45(4), 421-429.

14. Andersen, P. S., Pedersen, J. K., Fode, P., Skov, R. L., Fowler Jr, V. G., Stegger, M., \& Christensen, K. (2012). Influence of host genetics and environment on nasal carriage of Staphylococcus aureus in Danish middle-aged and elderly twins. The Journal of infectious diseases, 206(8), 1178-1184.

15. Leekha, S., Diekema, D. J., \& Perencevich, E. N. (2012). Seasonality of staphylococcal infections. Clinical microbiology and infection, 18(10), 927-933.

16. Moon, K. W., Huh, E. H., \& Jeong, H. C. (2014). Seasonal evaluation of bioaerosols from indoor air of residential apartments within the metropolitan area in South Korea. Environmental monitoring and assessment, 186(4), 2111-2120.

17. Jinnestål, C. L., Belfrage, E., Bäck, O., Schmidtchen, A., \& Sonesson, A. (2014). Skin barrier impairment correlates with cutaneous $\mathrm{S}$ taphylococcus aureus colonization and sensitization to skin-associated microbial antigens in adult patients with atopic dermatitis. International journal of dermatology, 53(1), 27-33.

18. Del Rio, A., Cervera, C., Moreno, A., Moreillon, P., \& Miró, J. M. (2009). Patients at risk of complications of Staphylococcus aureus bloodstream infection. Clinical Infectious Diseases, 48(Supplement_4), S246-S253.

19. Kuehnert, M. J., Hill, H. A., Kupronis, B. A., Tokars, J. I., Solomon, S. L., \& Jernigan, D. B. (2005). Methicillin-resistantStaphylococcus aureus hospitalizations, United States. Emerging infectious diseases, 11(6), 468.

20. Chambers, H. F., \& DeLeo, F. R. (2009). Waves of resistance: Staphylococcus aureus in the antibiotic era. Nature Reviews Microbiology, 7(9), 629-641.

21. Handel, A., Longini Jr, I. M., \& Antia, R. (2009). Intervention strategies for an influenza pandemic taking into account secondary bacterial infections. Epidemics, 1(3), 185-195. 
22. McCullers, J. A. (2011). Preventing and treating secondary bacterial infections with antiviral agents. Antiviral therapy, 16(2), 123.

23. Brook, I. (2002). Secondary bacterial infections complicating skin lesions. Journal of medical microbiology, 51(10), 808-812.

24. McLure, H. A., Talboys, C. A., Yentis, S. M., \& Azadian, B. S. (1998). Surgical face masks and downward dispersal of bacteria. Anaesthesia, 53(7), 624-626.

25. Raad, I., Abbas, J., \& Whimbey, E. (1997). Infection control of nosocomial respiratory viral disease in the immunocompromised host. The American journal of medicine, 102(3), 48-52.

26. MacIntyre, C. R., Wang, Q., Rahman, B., Seale, H., Ridda, I., Gao, Z. \& Moa, A. (2014). Efficacy of face masks and respirators in preventing upper respiratory tract bacterial colonization and co-infection in hospital healthcare workers. Preventive medicine, 62, 1-7.

27. Grinshpun, S. A., Haruta, H., Eninger, R. M., Reponen, T., McKay, R. T., \& Lee, S. A. (2009). Performance of an N95 filtering facepiece particulate respirator and a surgical mask during human breathing: two pathways for particle penetration. Journal of occupational and environmental hygiene, 6(10), 593-603.

28. Zhu, J. H., Lee, S. J., Wang, D. Y., \& Lee, H. P. (2014). Effects of long-duration wearing of N95 respirator and surgical facemask: a pilot study. J Lung Pulm Resp Res, 4, 97-100.

29. Li, Y., Wong, T., Chung, A. J., Guo, Y. P., Hu, J. Y., Guan, Y. T. \& Newton, E. (2006). In vivo protective performance of N95 respirator and surgical facemask. American journal of industrial medicine, 49(12), 1056-1065.

30. Roberge, R. J., Bayer, E., Powell, J. B., Coca, A., Roberge, M. R., \& Benson, S. M. (2010). Effect of exhaled moisture on breathing resistance of N95 filtering facepiece respirators. Annals of occupational hygiene, 54(6), 671-677.
31. Scarano, A., Inchingolo, F., \& Lorusso, F. (2020). Facial skin temperature and discomfort when wearing protective face masks: thermal infrared imaging evaluation and hands moving the mask. International Journal of Environmental Research and Public Health, 17(13), 4624.

32. Yip, W. L., Leung, L. P., Lau, P. F., \& Tong, H. K. (2005). The effect of wearing a face mask on body temperature. Hong Kong Journal of Emergency Medicine, 12(1), 23-27.

33. Keck, T., Leiacker, R., Heinrich, A., Kühnemann, S., \& Rettinger, G. (2000). Humidity and temperature profile in the nasal cavity. Rhinology, 38(4), 167-171.

34. Rosner, E. (2020). Adverse effects of prolonged mask use among health care professionals during COVID-19. J Infect Dis Epidemiol, 6, 130.

35. Purushothaman, P. K., Priyangha, E., \& Vaidhyswaran, R. (2020). Effects of Prolonged Use of Facemask on Healthcare Workers in Tertiary Care Hospital during COVID-19 Pandemic. Indian Journal of Otolaryngology and Head \& Neck Surgery, 1-7.

36. MacIntyre, C. R., Wang, Q., Seale, H., Yang, P., Shi, W., Gao, Z. \& Heywood, A. (2013). A randomized clinical trial of three options for N95 respirators and medical masks in health workers. American journal of respiratory and critical care medicine, 187(9), 960-966.

37. Smith, J. D., MacDougall, C. C., Johnstone, J., Copes, R. A., Schwartz, B., \& Garber, G. E. (2016). Effectiveness of N95 respirators versus surgical masks in protecting health care workers from acute respiratory infection: a systematic review and meta-analysis. Cmaj, 188(8), 567-574.

38. Desai, S. R., Kovarik, C., Brod, B., James, W., Fitzgerald, M. E., Preston, A., \& Hruza, G. J. (2020). COVID-19 and personal protective equipment: Treatment and prevention of skin conditions related to the occupational use of personal protective equipment. Journal of the American Academy of Dermatology, 83(2), 675-677.

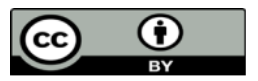

This work is licensed under Creative Commons Attribution 4.0 License

To Submit Your Article Click Here: Submit Manuscript

DOI: $10.31579 / 2690-1919 / 177$
Ready to submit your research? Choose Auctores and benefit from:

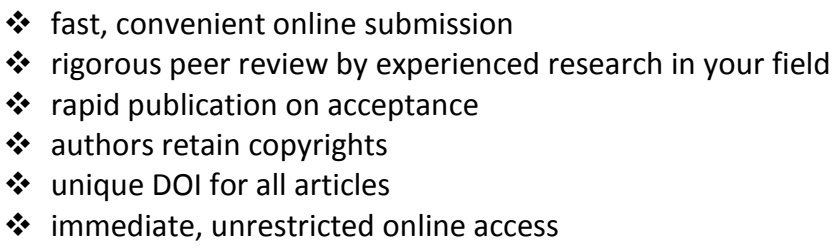

At Auctores, research is always in progress.

Learn more www.auctoresonline.org/journals/journal-of-clinicalresearch-and-reports 